\title{
Number Size Distribution of Ambient Particles in a Typical Urban Site: The First Polish Assessment Based on Long-Term (9 Months) Measurements
}

\author{
Krzysztof Klejnowski, Andrzej Krasa, Wioletta Rogula-Kozłowska, and Barbara Błaszczak
}

Institute of Environmental Engineering of the Polish Academy of Sciences, ul. Skłodowskiej Curie 34, 41-819 Zabrze, Poland

Correspondence should be addressed to Barbara Błaszczak; barbara.blaszczak@ipis.zabrze.pl

Received 5 July 2013; Accepted 6 August 2013

Academic Editors: P. Kumar and B. A. Schichtel

Copyright (C) 2013 Krzysztof Klejnowski et al. This is an open access article distributed under the Creative Commons Attribution License, which permits unrestricted use, distribution, and reproduction in any medium, provided the original work is properly cited.

This work presents results from the long-term measurements of particle number carried out at an urban background station in Zabrze, Poland. Ambient particles with aerodynamic diameters of between $28 \mathrm{~nm}$ and $10 \mu \mathrm{m}$ were investigated by means of a DEKATI thirteen-stage electrical low pressure impactor (ELPI). The particle number-size distribution was bimodal, whilst its density function had the local maxima in the aerodynamic diameter intervals $0.056-0.095 \mu \mathrm{m}$ and $0.157-0.263 \mu \mathrm{m}$. The average particle number in winter was nearly twice as high as in summer. The greatest number concentrations in winter were those of the particles with diameters of between 0.617 and $2.41 \mu \mathrm{m}$, that is, the anthropogenic particles from fossil fuel combustion. Approximately $99 \%$ of the particles observed in Zabrze had aerodynamic diameters $\leq 1 \mu \mathrm{m}$-they may have originated from the combustion of biomass, liquid, and gaseous fuels in domestic stoves or in car engines. The daily variation of particle number was similar for both seasons-the highest values were observed in the morning (traffic rush hour) and in the afternoon/late evening (traffic and house heating emissions). An additional maximum $(0.028-0.056 \mu \mathrm{m})$ observed in the early afternoon in summer was due to the intensive formation of new PM particles from gas precursors.

\section{Introduction}

In order to assess the influence of particulate matter (PM) on the air quality, ecosystems, human health, and climate changes, it is necessary to be aware of its chemical composition and size distribution [1-3]. As humans are the most important recipients of environmental pollutants, differences in relationships between specific PM fractions (their concentrations) and morbidity and mortality of the human population must be taken into consideration.

There is no concentration threshold for PM in the atmospheric air, below which the PM impact on the human health could be ignored [4]. The correlations between suspended particles and health effects, including mortality, have been discovered for increasingly lower concentration levels $[5,6]$. It is not clear which factors (i.e., PM mass concentration, number concentration, biological or chemical composition [7], physical properties, mass burden, particle number, total area, or electrostatic characteristics [8]) have the most crucial influence on human health. Nevertheless, the population exposed to PM always demonstrates adverse health effects.

Particles with aerodynamic diameters of between $10^{-3}$ and $100 \mu \mathrm{m}$ can occur everywhere in the ambient air. The number of particles with specific size present at a given site depends on many factors. These include the origin of PM at the discussed site [9], atmospheric processes (condensation, nucleation, and evaporation), chemical transformations, deposition, and removal with precipitation. It should be mentioned that particles with a diameter smaller than $100 \mathrm{~nm}$, known as ultrafine particles, dominate the number concentrations but do make a small contribution to total aerosol particle mass $[10,11]$. They represent excess health risks relative to fine $(d<2.5 \mu \mathrm{m})$ or coarse particles $(10 \mu \mathrm{m}<d<2.5 \mu \mathrm{m})$ of identical or similar chemical composition [12].

It is increasingly recognised that ultrafine particles can have significant implications on public health in addition 
to mass concentrations of particulate matter [10-12]. This is because ultrafine particles can easily be inhaled and deposited in the deeper regions of the respiratory tracts and have a higher surface area per unit volume than larger particles, thus increasing their capability to adsorb organic compounds, some of which are potentially carcinogenic [13]. Current legislation in Europe [14] requires mass concentration measurements of the $\mathrm{PM}_{10}$ and $\mathrm{PM}_{2.5}$ (ambient particles with aerodynamic diameter $\leq 10$ and $2.5 \mu \mathrm{m}$, resp.), whereas particle number concentration (including ultrafine particles) and size distribution are not routinely measured in monitoring networks $[13,15]$.

A number of studies described number concentration of $\mathrm{PM}$ in cities and urban surroundings [16-26]. It is clear that traffic is the most important source of ultrafine particles [17, 27, 28]. Emissions from gasoline- and diesel-fuelled vehicles alone can contribute to up to approximately $90 \%$ of the total particle number concentrations [29]. Kumar et al. [16] reports a summary of recently published studies on atmospheric nanoparticles in European cities. This covers a total of about 45 sampling locations in 30 different cities within 15 European countries for quantifying levels of roadside and urban background particle number concentrations (PNCs). Average PNCs at the reviewed roadside and urban background sites were found to be $3.82 \pm 3.25 \times 10^{4}$ and $1.63 \pm 0.82 \times 10^{4} \mathrm{~cm}^{-3}$, respectively, giving a roadside to background $\mathrm{PNC}$ ratio of $\sim 2.4$.

Biomass burning in local sources and nucleation processes significantly influence the particle number. Number concentrations are also affected by meteorological conditions [12]. Furthermore, PM concentrations and PM size distribution vary considerably in time and space [30]. For example, concentrations of nanoparticles can vary up to five or more orders of magnitude (from $10^{2}$ to $10^{7} \mathrm{~cm}^{-3}$ ) depending on environmental conditions and source strengths [15]. For these reasons, continuous PM measurements performed at many various sites, particularly in densely populated urban areas subject to high PM levels, seem extremely useful and practical.

Studies conducted in recent years prove that PM concentrations in Poland are often high or extremely high [31-33]. This fact, combined with the unclear character of number size distribution and the PM number concentration in the air, highlights the necessity to conduct continuous measurements in urban areas in Poland.

In terms of air protection, the Upper Silesian urban area is one of the most interesting regions, both in Poland and in Europe. Almost all industries (electrical, chemical, glassmaking, textile, clothing and ceramic ones, ferrous and nonferrous metallurgy, machine building, hard coal mining, and coking) have been actively taking part in the deterioration of the natural environment for nearly 200 years. On the other hand, the Upper Silesian urban area experienced the largest national decrease in industrial air pollution brought about by the last three decades of economic transformations in Poland (e.g., the yearly dust fall in Zabrze exceeded $2100 \mathrm{~g} / \mathrm{m}^{2}$ in the 1970s, oscillated between 700 and $800 \mathrm{~g} / \mathrm{m}^{2}$ in the 1980s, and was lower than $350 \mathrm{~g} / \mathrm{m}^{2}$ after the year 1995 [34]).
Consequently, the PM concentration dropped significantly (Figure 1; see [31]). It is worth mentioning that Upper Silesia is also affected by periodically occurring episodes of very high concentrations of air pollutants (especially $\mathrm{PM}_{2.5}$ and $\mathrm{PM}_{10}$ concentrations in city centers in winter [35]), which increase the yearly PM concentrations.

The aim of the following study was to examine the number concentration and number size distribution of $13 \mathrm{PM}$ fractions. The results discussed below come from the first long-term measurements (9 months) of particle number carried out in Poland.

\section{Apparatus and Measurement Site}

The measurement site selected for the experiment was located in Zabrze (Figure 2). It was representative for the air pollution conditions typical for the Upper Silesia urban area. Thus, it meets the requirements for the urban background site imposed by the Directive 2008/50/EC of the European Parliament and the Council [14]. Additionally, the impact of the industrial and municipal emissions on the Upper Silesia residential area was represented at this site and could be properly observed. Detailed description of measurement site surroundings was given elsewhere [34, 35].

Zabrze is one of the fourteen cities that form the Upper Silesia urban area. The area is located in the center of the Silesia province, Poland and occupies $141,230 \mathrm{~km}^{2}$. Its population is approximately 2.1 million (1,691 inhabitants per $\left.1 \mathrm{~km}^{2}\right)$. It is one of the most urbanized and industrialized regions of Central Europe. About $50 \%$ of the Silesia province gross product and $7 \%$ of the national GDP come from the Upper Silesian urban area. Six European capitals (Berlin, Prague, Vienna, Bratislava, Budapest, and Warsaw) lie within $600 \mathrm{~km}$ distance from Katowice, the Silesia province capital. The main transport routes linking Poland with Western Europe run in all directions across this region.

The Electrical Low Pressure Impactor (ELPI, manufactured by DEKATI) was used to examine the number concentration and number size distribution. ELPI is used worldwide in continuous air quality monitoring for assessing PM size distribution and PM concentrations. It is often employed in examinations of dusts emitted from industrial sources or motor vehicles [14, 37-44].

The main components of ELPI are

(i) corona charger, used to charge particles with a known charge before they are collected in the impactor stages;

(ii) low-pressure cascade impactor, used for size distribution of PM; it consists of 13 electrically insulated (PTFE isolators) stages, whose cut-off diameters gradually decrease; its first stage is the preselection stage;

(iii) multichannel electrometer, used for measuring electric current that appears when particles are collected in different impactor stages; current intensity values constitute rough results obtained from the ELPI unit; they form the basis for calculating remaining output, 


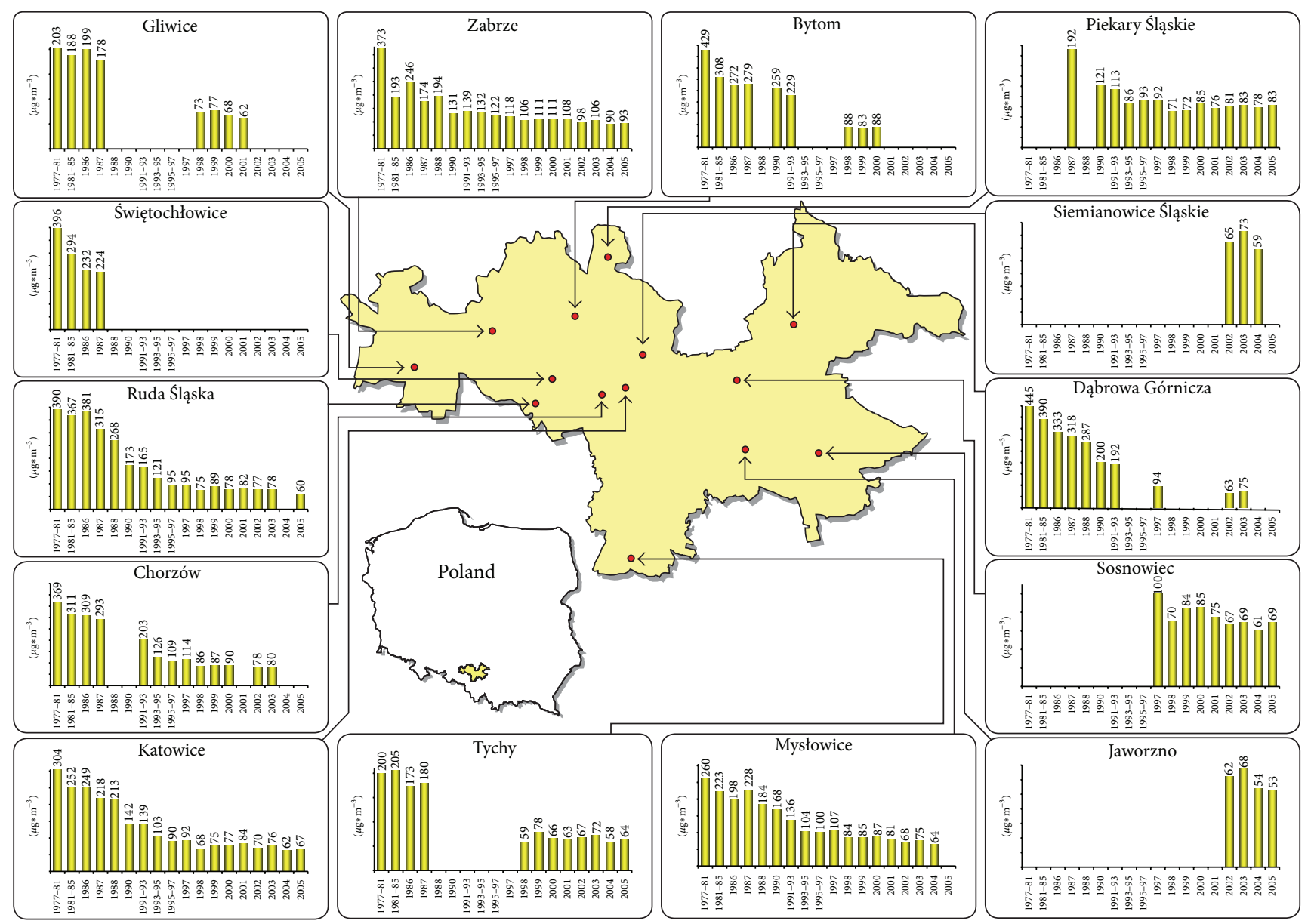

FIGURE 1: Total PM concentrations $\left(\mu \mathrm{g} / \mathrm{m}^{3}\right)$ in 14 cities of the Upper Silesian urban area in the years 1977-2005 (figure taken from study [31]).

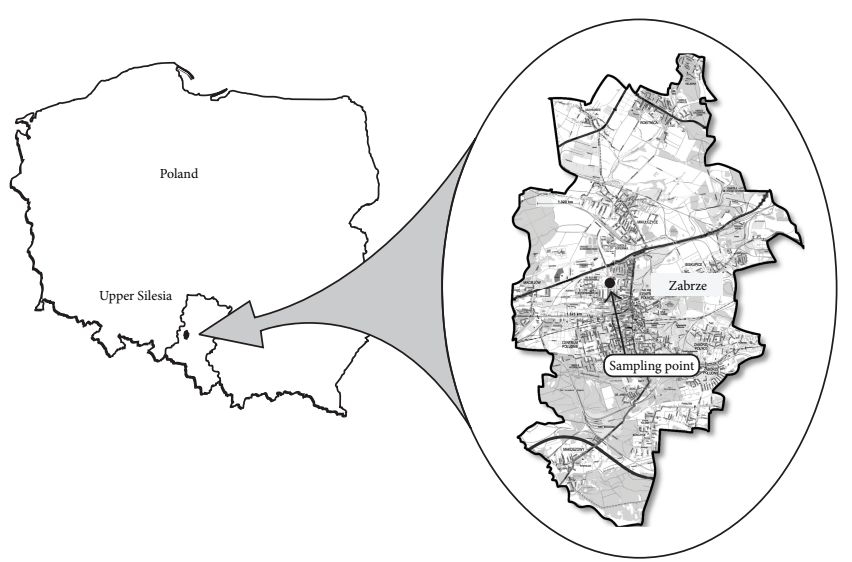

Figure 2: Measurement point location (figure taken from study [36]).

that is, distribution of particle number, size, area, mass, and volume.

The course of the measurement process and specific instrument parameters were controlled with the computer and ELPI VI software.
Number size distribution was measured in real time for particles with aerodynamic diameters between 0.03 and $10 \mu \mathrm{m}$. The measurements took place between January 1, 2010, and October 7, 2010. They were carried out in series lasting between six and fourteen days, depending on the concentration of total suspended particles (TSP) in the given period (necessary impactor clean-up-one day lasting technical break). Seventy measurement series were performed in total. ELPI was installed in an air-conditioned measurement container. The inlet with a sampling head for TSP was placed at the height of $4.5 \mathrm{~m}$ above the ground level.

\section{Results and Discussion}

The results are presented in several specific subsections focusing on the main questions that prompted this study.

3.1. Particle Number Concentrations. Descriptive statistics for sets of number concentrations (concentration is the amount of PM particles per $\mathrm{cm}^{3}$ ) of $13 \mathrm{PM}$ fractions at the urban location site are given in Tables 1 and 2. The basic averaging time for results obtained with ELPI (moving average) was 1 minute. 1-minute concentrations were averaged to 1 hour (Table 1), whereas 24-hour concentrations were calculated 
on the basis of average 1-hour concentrations (Table 2). Average concentrations were calculated twice during the measurement period. The first calculation was based on 1-hour concentrations, while the second one was based on 24-hour concentrations. The results were averaged for three measurements ranges, that is, for the entire research period (January 1, 2010-October 7, 2010), winter (January 1, 2010March 31, 2010, and October 1, 2010-October 7, 2010), and summer (April 1, 2010-September 30, 2010).

The total number concentration (sum of average concentrations of all fractions) for the entire research period (January 1, 2010-October 7, 2010) was comparable to sets of 1-hour (Table 1) and 24-hour concentrations (Table 2). It was $6227.76 \mathrm{~cm}^{-3}$ and $6063.5 \mathrm{~cm}^{-3}$, respectively. The discrepancy could result from short-term episodes of high particle concentrations in the air, which could have considerable impact on the value of the average 24-hour number concentration [15].

It is useful to compare the results obtained in this study with those obtained in similar studies around the world (Table 3). At first, it is worth mentioning that the differences in the observed number concentrations resulted, in a large degree, from different characteristics of the measurement sites, dissimilar local conditions, distinct periods of result averaging, and diverse measurement instruments [12].

In general, the total number concentration of PM in Zabrze was lower than number concentrations of ambient particles at the majority of measurement sites in Europe, with the exception of values recorded in Vienna, Prague, Hohenpeißenberg, and Budapest (Table 3). However, in winter the average number of particles in Zabrze was similar to the results obtained in other places.

The results listed in Table 3 suggested that PM number concentration in Zabrze is mainly influenced by primary emissions, whereas in other European regions, gas-to-particle conversion mostly affected on aerosol number. It was clearly visible in the Hohenpeißenberg research, where the higher particle number was observed in summer, when meteorological conditions were favorable to the formation of secondary aerosol particles. Moreover, it is a fact that mass concentrations of $\mathrm{PM}_{2.5}$ and $\mathrm{PM}_{10}$ in Zabrze have nearly the highest values in Europe [34, 45].

The number concentrations of PM generally decrease with increasing particle diameter [15]. Over $80 \%$ of the airborne particles in the urban air are in the ultrafine size range [21].

The measurements conducted in Zabrze revealed that $99 \%$ of airborne particles have diameters $\leq 1 \mu \mathrm{m} . \mathrm{PM}_{0.056}$ constituted $44 \%$ of the total number concentration, whereas $\mathrm{PM}_{0.156}$ and $\mathrm{PM}_{0.263}$ made $62 \%$ and $79 \%$ of the total number concentration of PM (Table 1). Similar results were obtained at the urban site in Milan, Italy. The number concentrations of ultrafine and submicron particles constituted $78 \pm 5 \%$ and $22 \pm 5 \%$ of the total number concentration in winter and $79 \pm 5 \%$ and $21 \pm 5 \%$ of the total number concentration in summer, respectively [46].

The obtained results corroborated the fact that ultrafine particles had the largest share in the total PM number concentration observed in Zabrze. Consequently, this meant that the PM in Zabrze came mainly from combustion (fossil fuel, biomass, petrol, and gas) and transformations of gaseous precursors of PM.

It should be noted that ultrafine particles constitute a major threat for the local inhabitants and environment $[3,47-$ 49]. For example, it was found that inhaled or instilled ultrafine PM particles induce pulmonary inflammation, oxidative stress, and distal organ involvement in animals [50-52]. Moreover, they can also induce or exacerbate pulmonary and cardiovascular diseases in humans, such as COPD and asthma in children and compromised adults [16, 52-54].

\subsection{Seasonal Variation of Particle Number Concentrations.} Measurements conducted at background site in Zabrze, which lasted for 9 months, revealed also distinct seasonal variation of particle number concentrations. In winter, the total average particle number in the air, whether for the averaged 1-hour or 24-hour results, was nearly twice as high as the analogous averaged value calculated for summer (Tables 1 and 2). It was 8797.87 and $4946.9 \mathrm{~cm}^{-3}$ (sets of 1-hour concentrations) and 8461.72 and $4915.07 \mathrm{~cm}^{-3}$ (sets of 24-hour concentrations) for winter and summer seasons, respectively. The visible seasonal variation was observed not only for the total number concentration but also for all PM fractions.

While analyzing seasonal changes in the total particle number concentrations, it was found that total PM number concentrations were 1.78 times higher in winter than in summer. However, while analyzing seasonal changes in the particle number within particular aerodynamic diameter ranges, it was observed that increases in particle number varied considerably and ranged from 1.22 to 4.29 . The largest one occurred for diameters between 0.617 and $2.41 \mu \mathrm{m}$ (3.184.29). The lowest one occurred for fractions between 0.028 and $0.056 \mu \mathrm{m}(1.2-1.5)$ - Tables 1 and 2 .

Generally, the maximum values observed for sets of 1hour and 24-hour concentrations were also higher in winter, with the exception of the maximum number concentrations of the following fractions: $0.028-0.056 \mu \mathrm{m}, 0.056-0.095 \mu \mathrm{m}$, $0.384-0.617 \mu \mathrm{m}$, and $0.617-10.0 \mu \mathrm{m}$. For particles from the $0.028-0.617 \mu \mathrm{m}$ range it was caused by intensive nucleation processes occurring in summer (higher solar radiation intensity and high relative air humidity). Coarser particles originated mainly from mechanical processes, particularly road and soil erosion, and from biogenic sources such as vegetation-derived primary bioaerosol (e.g., pollen, spores, and plant debris). Consequently, their higher concentrations were observed in a dry and warm period (summer).

A visible seasonal variation of PM number concentration was also observed in other European cities (e.g., see [10, 12, $15,46])$. For example, the total number concentration and number concentration of ultrafine (particles with diameter less than $100 \mathrm{~nm}$ ) and submicron particles (particles with diameter between 100 and $1000 \mathrm{~nm}$ ) in winter were nearly twice as high as summer concentrations, in measurements conducted at the urban site in Milan, Italy [46]. Similar observations were made at other measurement sites in Europe $[10,21,60]$. 


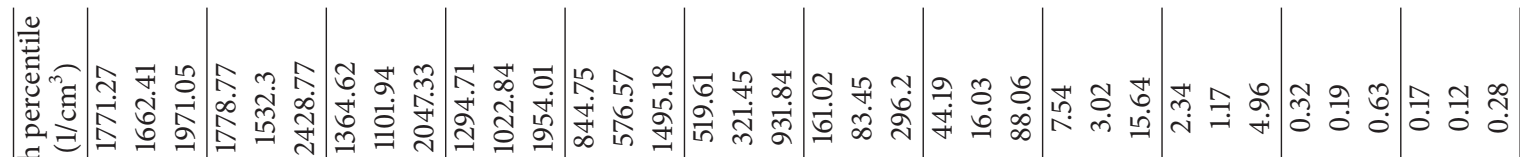
究

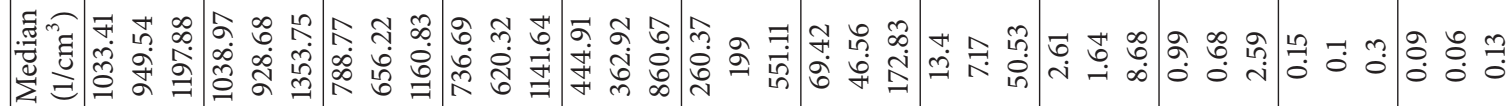

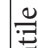

च⿹ 声 茎

:ํㅗำ

舟島央

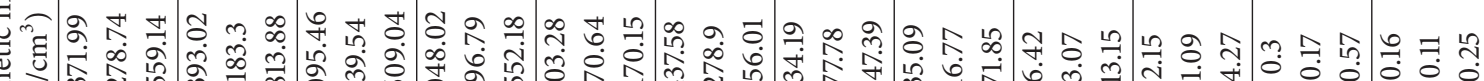
चू

\section{ב.}

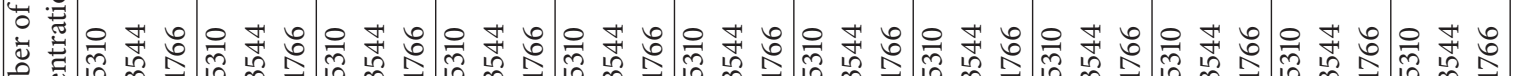

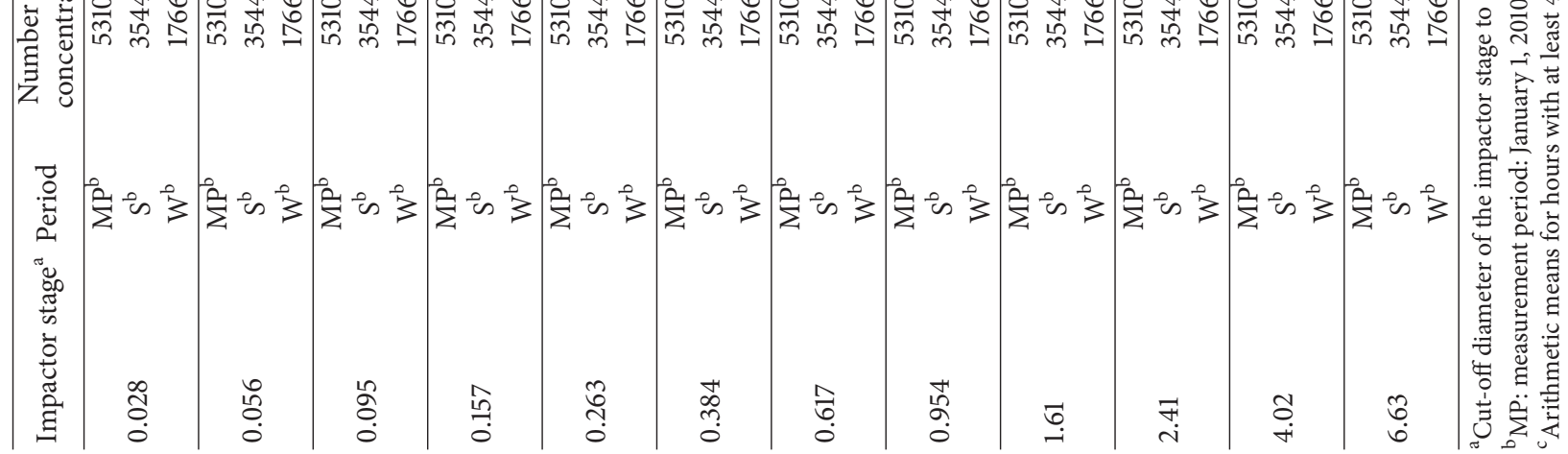




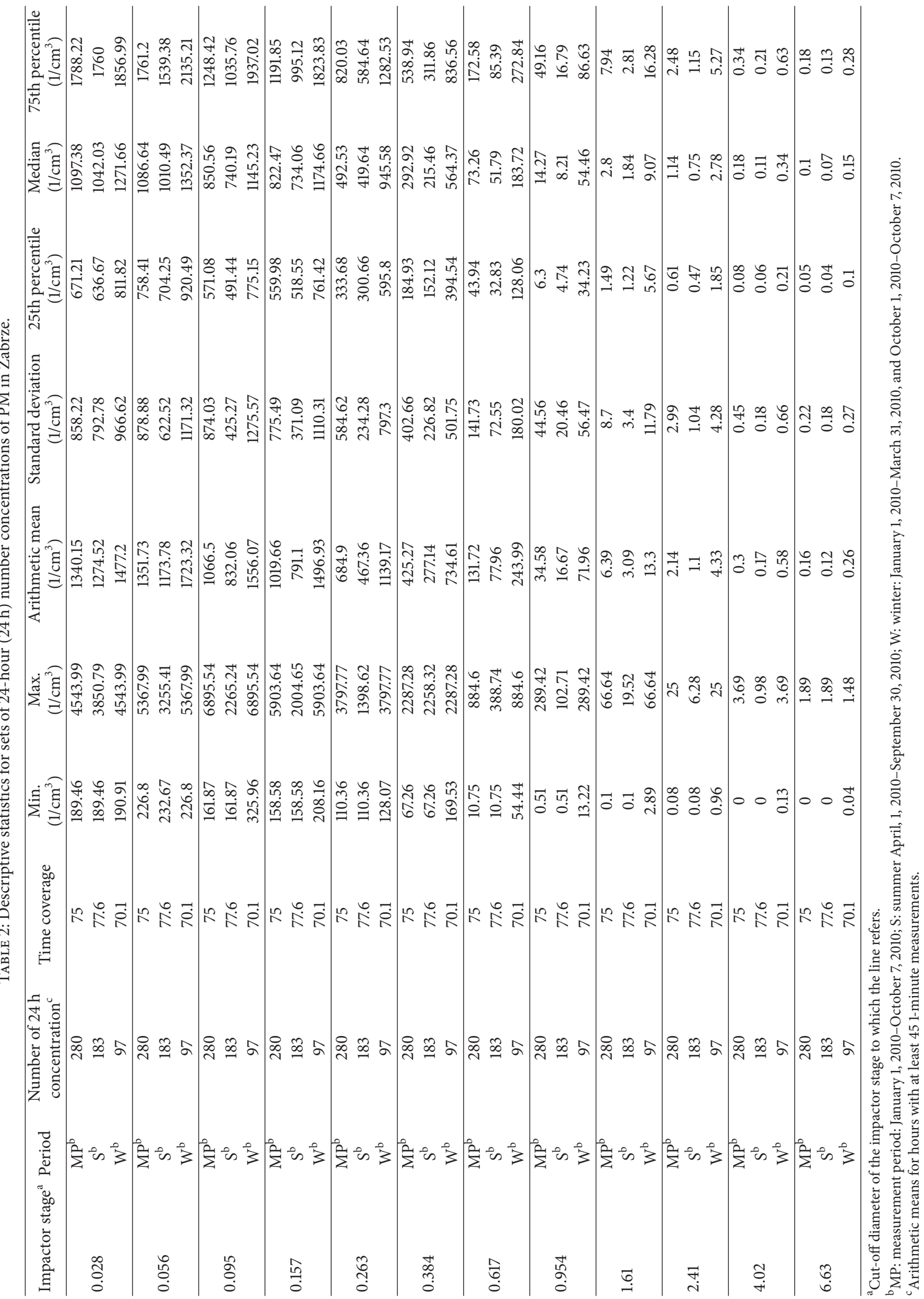


TABLE 3: Average number concentrations of PM observed at various urban background sites in the world.

\begin{tabular}{|c|c|c|c|}
\hline Country & City, measurement period & Number concentration $\left(\mathrm{cm}^{-3}\right)$ & Reference \\
\hline Poland & Zabrze, Jan.-Oct. $2010^{1}$ & $\begin{array}{c}\text { Whole period: } 6.23 \cdot 10^{3} \\
\text { Summer: } 4.95 \cdot 10^{3} \\
\text { Winter: } 8.80 \cdot 10^{3}\end{array}$ & The following study \\
\hline Austria & Vienna & $8.0 \cdot 10^{3}$ & {$[12]$} \\
\hline Czech Republic & Prague & $7.3 \cdot 10^{3}$ & {$[12]$} \\
\hline Finland & Helsinki, 2001-2003 & $\begin{array}{c}\text { Weekdays: } 1.1 \cdot 10^{4} \\
\text { Weekends: } 0.69 \cdot 10^{4}\end{array}$ & {$[10]$} \\
\hline France & Marseille, 2002-2003 & $1 \cdot 10^{4}$ & [55] \\
\hline \multirow{2}{*}{ Germany } & Augsburg, 2001-2003 & $\begin{array}{c}\text { Weekdays: } 1 \cdot 10^{4} \\
\text { Weekends: } 0.82 \cdot 10^{4}\end{array}$ & {$[10]$} \\
\hline & Hohenpeißenberg, 2003-2004 & $\begin{array}{l}\text { Summer: } 3.10 \cdot 10^{3} \\
\text { Winter: } 1.81 \cdot 10^{3}\end{array}$ & {$[15]$} \\
\hline Greece & Athens, 2002-2003 & $1 \cdot 10^{4}$ & {$[55]$} \\
\hline Hungary & Budapest & $10.6 \cdot 10^{3}$ & {$[12]$} \\
\hline \multirow[b]{2}{*}{ Italy } & Rome, 2001-2003 & $4.3 \cdot 10^{4}$ & {$[10]$} \\
\hline & Milan, Sept 2003-Aug 2004 & $\begin{array}{l}\text { Cold season: } 2.5 \cdot 10^{4} \\
\text { Warm season: } 1.3 \cdot 10^{4}\end{array}$ & [46] \\
\hline The Netherlands & Utrecht, Oct.-Nov. 2008 & $\begin{array}{l}\text { Street location: } 3.86 \cdot 10^{4} \\
\text { Suburban background: } 133 \cdot 10^{4} \\
\text { City background: } 141 \cdot 10^{4}\end{array}$ & {$[56]$} \\
\hline \multirow[t]{2}{*}{ Spain } & Barcelona, 2001-2003 & $\begin{array}{l}\text { Weekdays: } 3.9 \cdot 10^{4} \\
\text { Weekends: } 2.76 \cdot 10^{4}\end{array}$ & {$[10]$} \\
\hline & Barcelona, 2003-2004 & $2.3 \cdot 10^{4}$ & {$[10]$} \\
\hline Sweden & Stockholm, 2001-2003 & $\begin{array}{l}\text { Weekdays: } 1.0 \cdot 10^{4} \\
\text { Weekends: } 0.8 \cdot 10^{4}\end{array}$ & {$[10]$} \\
\hline Switzerland & Zurich, 2001-2002 & $4.7 \cdot 10^{4}$ & {$[20]$} \\
\hline UK & London, 2004-2005 & $5 \cdot 10^{4}$ & {$[57]$} \\
\hline Australia & Brisbane & $1.5 \cdot 10^{4}$ & {$[58]$} \\
\hline USA & Atlanta, 1998-1999 & $9.7 \cdot 10^{4}$ & [59] \\
\hline
\end{tabular}

${ }^{1}$ Values given in the table were obtained on the basis of average 1-hour concentrations (Table 1).

A more intensive impact from house heating in winter and meteorological conditions that influenced the boundary layer height (mixing layer) could be the reasons for the observed seasonal variation. During winter atmospheric conditions were significantly more stable, which resulted in the stagnation of pollutants and prevented their dispersion in the air $[46,61]$. On the contrary in summer period the boundary layer is higher than in winter for the stronger convection induced by the solar radiation, resulting in a greater vertical dilution of the pollutants [46]. Moreover, in spring and summer higher concentration of aerosol precursor gases may allow photochemical reactions to produce condensable gases and subsequent nucleation and growth in urban [21]. It would result in increased particle number concentration for ultrafine particles. The study by Borsós et al. demonstrated that elevated PM number concentrations were mainly observed in summer months, particularly for ultrafine particles [12]. Number concentrations were also the highest in summer $\left(3101 \mathrm{~cm}^{-3}\right)$ and lowest in winter $\left(1807 \mathrm{~cm}^{-3}\right)$ at the rural background site in Hohenpeißenberg, Germany [15].
The enhanced concentrations in winter would be attributed especially to particulate emissions from domestic heating and power generation sector [60].

3.3. Number Size Distribution. Figure 3 presents number size distribution for the discussed periods calculated on the basis of 1-hour and 24-hour concentrations. Many authors demonstrate $[12,46,56,62]$ that the number size distribution of PM is rather dynamic. It reflects the influence of emission sources as well as processes of PM particles formation, transformation, and transportation in the atmosphere.

Whether it was established on the basis of 1-hour or 24hour concentrations (Figure 3 ), the number size distribution was unimodal within the entire measurement period in 2010. The maximum of number size distribution occurred for the $0.157-0.263 \mu \mathrm{m}$ fraction (Figures 3(a) and 3(c)). The number size distribution was bimodal in shorter time periods, namely, for 1-hour concentration distribution in winter and 24-hour concentration distribution in summer (the second distribution maximum for the $0.056-0.095 \mu \mathrm{m}$ fraction). 


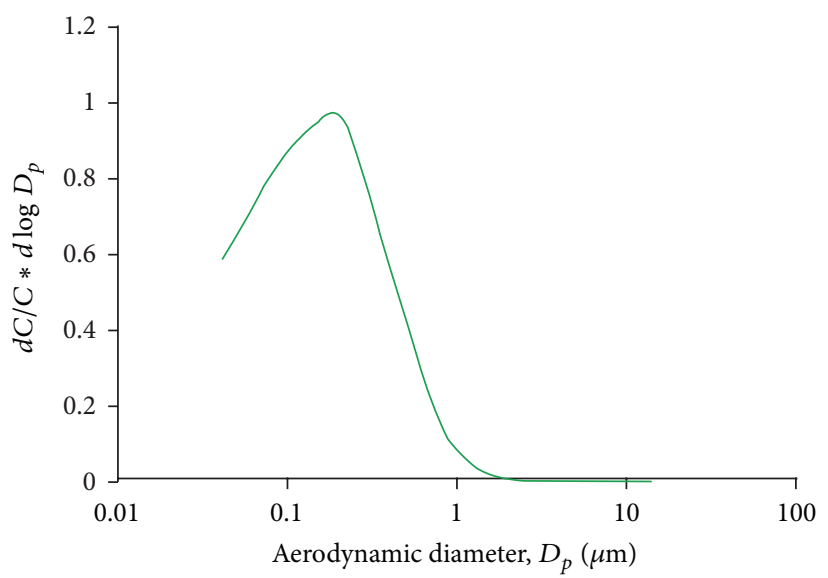

- Measurement period

(a)

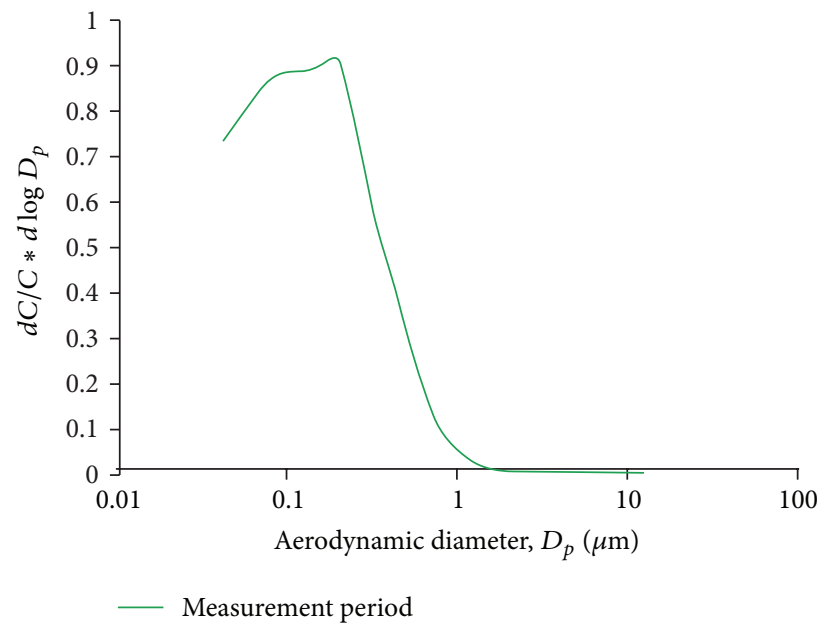

(c)

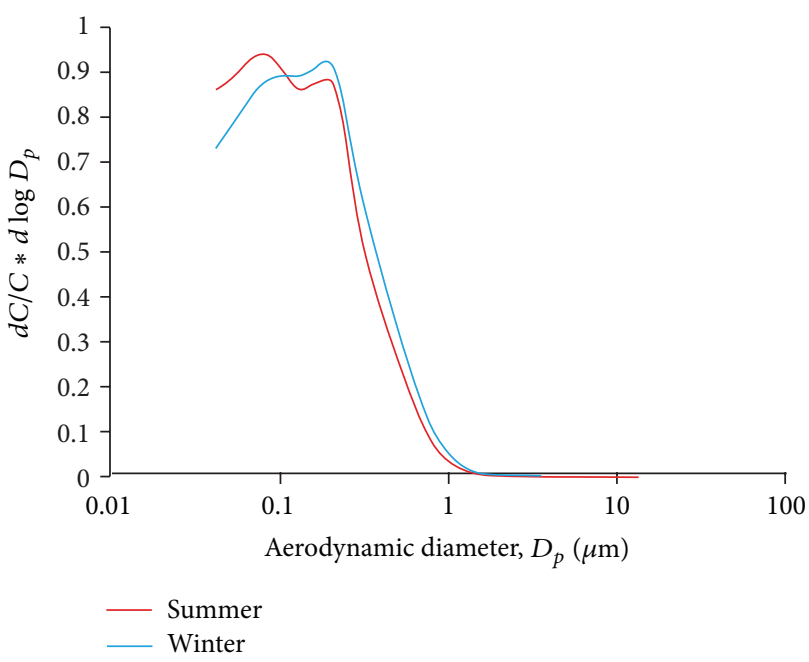

(b)

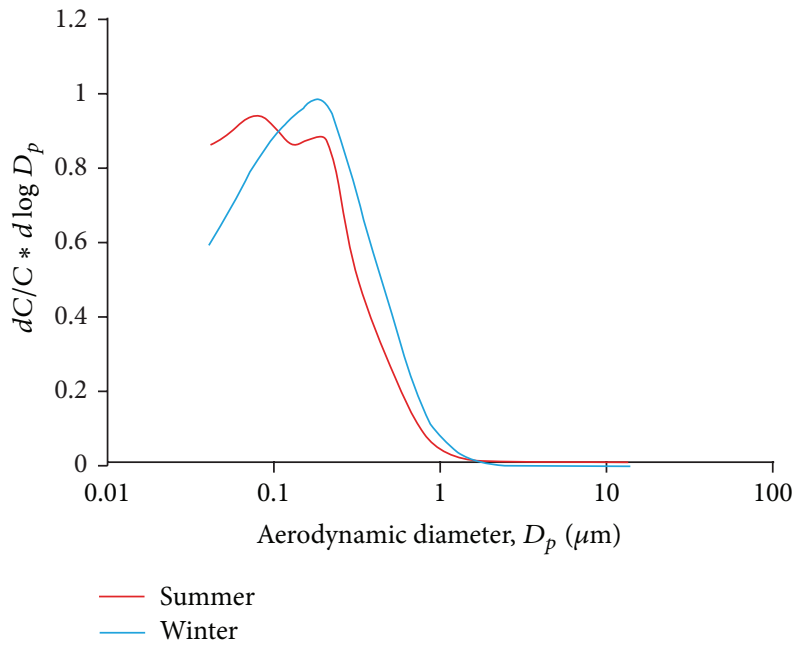

(d)

Figure 3: Number size distribution: (a) 1-hour concentrations, for entire measurement period (January 1, 2010-October 7, 2010); (b) 1-hour concentrations, in summer (April 1, 2010-September 30, 2010) and winter (January 1, 2010-March 31, 2010, and October 1, 2010-October 7, 2010); (c) 24-hour concentrations, for entire measurement period (January 1, 2010-October 7, 2010); (d) 24-hour concentrations, in summer (April 1, 2010-September 30, 2010) and winter (January 1, 2010-March 31, 2010, and October 1, 2010-October 7, 2010).

Similar results were obtained in Zabrze in 2008. The research concerned analyses of mass size distribution of PM [63]. The maxima of mass size distribution occurred for the $0.26-0.4 \mu \mathrm{m}$ fraction in summer and for the $0.17-0.26 \mu \mathrm{m}$ fraction both in winter and in the entire measurement period.

The distribution of ambient particles as a function of particle size, whether in urban or remote air, is typically characterised by three main modes [64]: the nucleation mode, the accumulation mode, and the coarse mode. The modes reflect the dominant processes giving rise to ambient PM [3]. Nucleation mode particles derive from chemical and physical processes, such as nucleation and condensation of supersaturated vapours produced by combustion. Accumulation mode particles mainly come from the growth of nucleation mode particles by coagulation, whereas most of coarse mode particles originate from anthropogenic and natural mechanical processes [65]. The coarse mode particles are usually primary particles generated by mechanical abrasion processes, but may contain other constituents as a result of coagulation and condensation processes [3].

The results showed that maxima of number size distribution fall into accumulation mode particles (with aerodynamic diameter between $100 \mathrm{~nm}$ and $1000 \mathrm{~nm}$ ). Nucleation mode particles are short-lived (minutes to hours) and grow by coagulation or vapour adsorption to form the accumulation mode. Particles in this latter size range can remain suspended for several days since further growth is inefficient and gravitational settling and deposition are slow [3].

Observed seasonal variation of particle number concentration in Zabrze was linked with occurrence of additional maximum for nucleation mode particles (Figures $3(\mathrm{~b})$ and $3(\mathrm{~d})$ ). Its presence might be related to the significant 


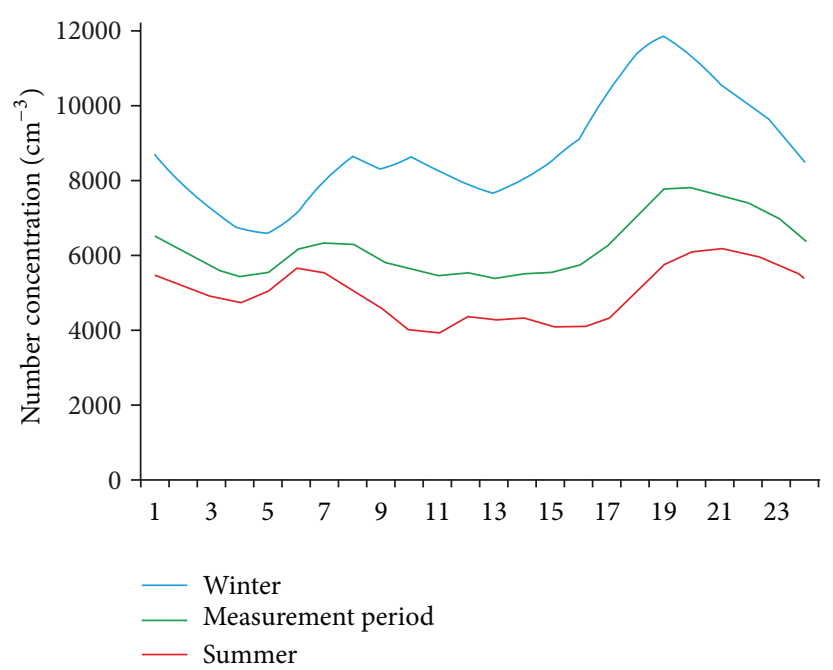

(a)

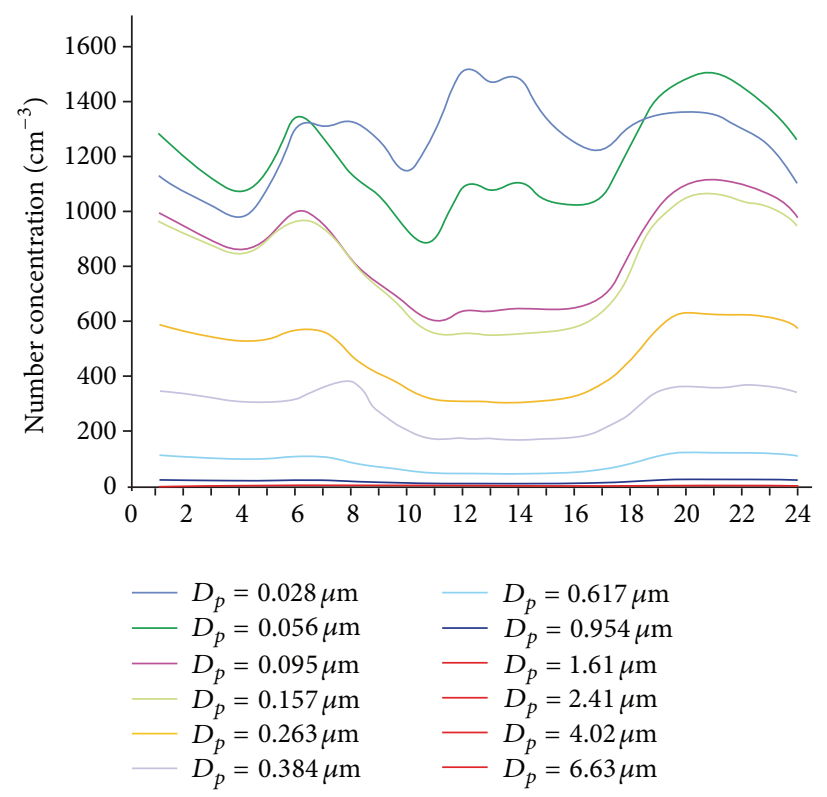

(c)

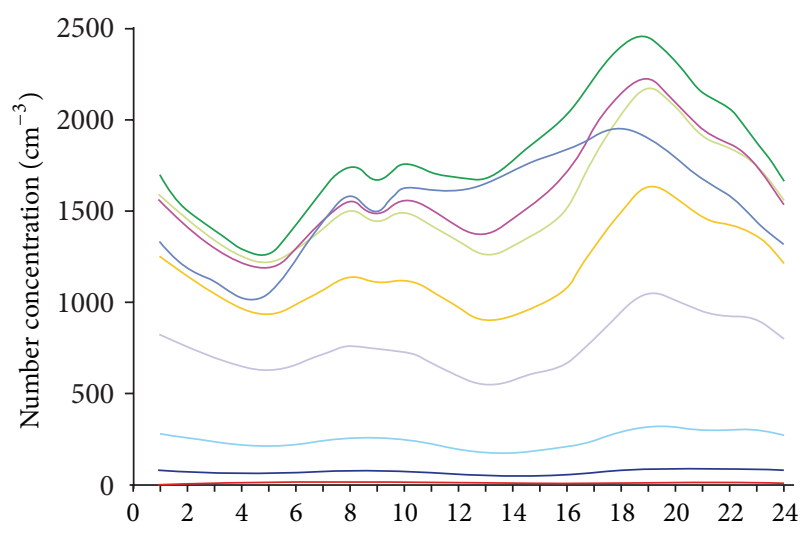

$$
\begin{aligned}
& \longrightarrow D_{p}=0.028 \mu \mathrm{m} \quad-D_{p}=0.617 \mu \mathrm{m} \\
& \longrightarrow D_{p}=0.056 \mu \mathrm{m} \quad \longrightarrow D_{p}=0.954 \mu \mathrm{m} \\
& -D_{p}=0.095 \mu \mathrm{m} \quad-D_{p}=1.61 \mu \mathrm{m} \\
& D_{p}=0.157 \mu \mathrm{m} \quad-D_{p}=2.41 \mu \mathrm{m} \\
& \longrightarrow D_{p}=0.263 \mu \mathrm{m} \quad-D_{p}=4.02 \mu \mathrm{m} \\
& \longrightarrow D_{p}=0.384 \mu \mathrm{m} \quad-D_{p}=6.63 \mu \mathrm{m}
\end{aligned}
$$

(b)

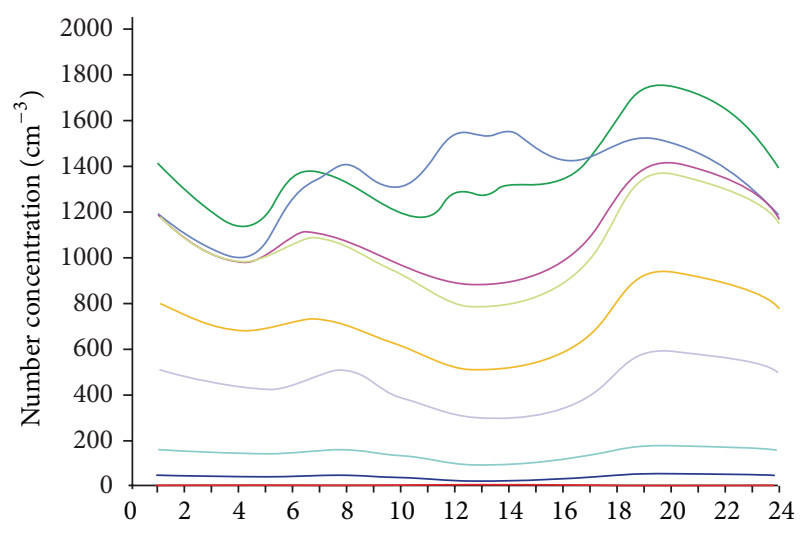

$$
\begin{array}{rlrl}
-D_{p} & =0.028 \mu \mathrm{m} & -D_{p} & =0.617 \mu \mathrm{m} \\
-D_{p} & =0.056 \mu \mathrm{m} & -D_{p} & =0.954 \mu \mathrm{m} \\
D_{p} & =0.095 \mu \mathrm{m} & -D_{p}=1.61 \mu \mathrm{m} \\
D_{p} & =0.157 \mu \mathrm{m} & -D_{p}=2.41 \mu \mathrm{m} \\
D_{p} & =0.263 \mu \mathrm{m} & -D_{p}=4.02 \mu \mathrm{m} \\
D_{p} & =0.384 \mu \mathrm{m} & -D_{p}=6.63 \mu \mathrm{m}
\end{array}
$$

(d)

FIGURE 4: Changes in the total particle number 1-hour concentrations (a) and particle number of the 13 PM fractions; (b) 1-hour concentrations in winter (January 1, 2010-March 31, 2010, and October 1, 2010-October 7, 2010); (c) 1-hour concentrations in summer (April 1, 2010September 30, 2010); (d) 1-hour concentrations entire measurement period (January 1, 2010-October 7, 2010), within 24-hour period.

contribution of secondary products of precursor transformations in the total number of PM observed in Zabrze. The seasonal variation of nucleation episodes was related to local characteristics, such as solar radiation intensity, air temperature, relative humidity, biogenic emissions, wind speed, and the atmospheric boundary level height, as well as the PM concentration and PM size distribution $[12,66-$ 68 ]. In winter period the occurrence of second maximum for nucleation mode particles might have resulted from combustion processes, much more intensive in cold months, which emit large quantities of gaseous precursors [11].

3.4. Daily Variation. The number concentration of PM was visibly variable within a short time period (few hours)Figure 4. Generally, the most significant variation was observed for the finest particles.

In winter, the number concentration of PM increased in the morning (6.00-10.00). A visibly large increase was also 
observed in the late afternoon and evening. In summer, maximum particle concentrations occurred at a slightly earlier time (5.00-8.00) in the morning. The evening maximum was observed at a slightly later time than in winter.

The number size distribution of PM for averaged results at each hour, observed for the entire measurement period, was unimodal with the maximum for the range of $0.157-0.263 \mu \mathrm{m}$. The second maximum $(0.056-0.095 \mu \mathrm{m})$ was observed for averaged results at each hour in two periods (18.00-23.00 and $5.00-8.00)$ in summer and early afternoon (12.00-14.00) in summer and in winter.

The daily patterns of particle number concentrations are interpreted in the light of the daily patterns of the emission sources and of the evolution of the main meteorological factors affecting the dispersion of atmospheric pollutants [46]. The variation in 1-hour concentrations within 24-hour period was similar in both measurement periods (summer and winter). However, for the summer, due to the less intensity of domestic heating emissions and to the different evolution of the boundary layer (earlier rise in the morning, higher height in the afternoon, and later fall in the evening), the concentration levels are quite different compared to the winter.

The morning and afternoon maxima of number size distribution of PM occurred both in winter and in summer, which could result from traffic emissions at rush hours [57]. It is noted that the mixing of the boundary layer is also increased during the early morning hours because of increasing sun radiation [10]. The number concentrations of all fractions decreased steadily from 10:00 PM towards noon. This feature is ascribed to the dilution of the emitted pollutants in an increasingly well-mixed boundary layer more than changes in traffic density [60]. The second maximum of number size distribution does not appear during the afternoon rush hours but shows up in the late evening. The shifts of the second peak into the late evening hours can be mainly explained by the effect of meteorology [12]. House heating, especially in winter season, could possibly contribute to the high PM number concentration observed at late evening hours [12, 22, 25]. The additional summer maximum of the number size distribution (occurring for the finest particles) in the early afternoon could be influenced by nucleation events. Such processes occur intensively in the presence of strong solar radiation $[60,67]$.

The daily variation of the PM number concentration at the urban site in Zabrze was similar to its variations observed in other European cities $[10,12,23,46,60]$.

\section{Conclusions}

Particle number concentration and number size distribution of atmospheric particles in the aerodynamic diameter range from 0.028 to $10 \mu \mathrm{m}$ were determined in Zabrze at urban background location. Particle number concentration in thirteen size fractions and their diurnal and seasonal variations were derived and compared. The measurements embraced seasons typical for the Upper Silesian urban area (heating/nonheating ones, winter/summer), which differed in meteorological and emission conditions. The following facts were established.

(1) Presence of 2 maxima (for ranges of $0.056-0.095 \mu \mathrm{m}$ and $0.157-0.263 \mu \mathrm{m}$ ) of number size distribution of PM occurred in Zabrze.

(2) Long-term measurements at urban background site in Zabrze revealed distinct seasonal patterns. The average particle number in winter was nearly twice as high as in summer, regardless of the averaging time (24 hours, 1 hour), as consequence of more frequent inversion situations and enhanced particulate emissions.

(3) In comparison with summer, the largest increase in the particle number observed in winter concerned particles with diameters between 0.617 and $2.41 \mu \mathrm{m}$, that is, fractions of the particles emitted from combustion processes.

(4) In comparison with summer, the lowest increase in the particle number observed in winter concerned particles with diameters between 0.028 and $0.056 \mu \mathrm{m}$, that is, particles from processes of gas transformations in precursors.

(5) Measurements conducted in Zabrze revealed that most of the background particle number concentration was derived from submicron particles. $\mathrm{PM}_{1}$ constituted 99\% of all particles observed in Zabrze.

(6) Particle number concentrations were highly variable on a time scale of several hours. The variation in the average 1-hour particle number within 24 hours was similar for both seasons. The highest values of particle concentrations were observed for two periods, that is, in the morning (traffic rush hour, 7.00-10.00) and in the afternoon or late evening (traffic and house heating emissions). An additional maximum was observed in the early afternoon in summer. The particle size $(0.028-0.056 \mu \mathrm{m})$ proved that the maximum was related to the intensive formation of new PM particles from gas precursors at that time of day.

(7) The diurnal cycles of particle number concentrations resemble the time-activity pattern of inhabitants, particularly in the pattern of road traffic flow, and are affected by meteorological circumstances. Traffic was found to be important source of ultrafine particles. Fossil fuel combustion from local sources and atmospheric nucleation contribute substantially. Diurnal variations of the intensities of these sources, particularly in road traffic, exhibit analogies for other urban areas.

(8) In general, PM number concentration at the Zabrze urban background site was lower than number concentrations at the majority of measurement sites in Europe.

In order to be able to study urban aerosol dynamics and the possible health effects of aerosol particles long continuous 
data sets are needed. The present data is a good example of this kind of data set, which can be used for different purposes.

\section{References}

[1] M. O. Andreae and P. J. Crutzen, "Atmospheric aerosols: biogeochemical sources and role in atmospheric chemistry," Science, vol. 276, no. 5315, pp. 1052-1058, 1997.

[2] P. H. McMurry, "A review of atmospheric aerosol measurements," Atmospheric Environment, vol. 34, no. 12-14, pp. 19591999, 2000.

[3] M. R. Heal, P. Kumar, and R. M. Harrison, "Particles, air quality, policy and health," Chemical Society Reviews, vol. 41, no. 19, pp. 6606-6630, 2012.

[4] World Health Organization, Air Quality Guidelines, World Health Organization, Geneva, Switzerland, 1999.

[5] M. L. Bell, J. M. Samet, and F. Dominici, “Time-series studies of particulate matter," Annual Review of Public Health, vol. 25, pp. 247-280, 2004.

[6] S. Vedal, M. Brauer, R. White, and J. Petkau, "Air pollution and daily mortality in a city with low levels of pollution," Environmental Health Perspectives, vol. 111, no. 1, pp. 45-52, 2003.

[7] J. G. Wilson, S. Kingham, J. Pearce, and A. P. Sturman, "A review of intraurban variations in particulate air pollution: implications for epidemiological research," Atmospheric Environment, vol. 39, no. 34, pp. 6444-6462, 2005.

[8] C. Monn, "Exposure assessment of air pollutants: a review on spatial heterogeneity and indoor/outdoor/personal exposure to suspended particulate matter, nitrogen dioxide and ozone," Atmospheric Environment, vol. 35, no. 1, pp. 1-32, 2001.

[9] S. K. Friedlander, "The characterization of aerosols distributed with respect to size and chemical composition-II: classification and design of aerosol measuring devices," Journal of Aerosol Science, vol. 2, no. 3, pp. 331-340, 1971.

[10] P. Aalto, K. Hämeri, P. Paatero et al., "Aerosol particle number concentration measurements in five European cities using TSI3022 condensation particle counter over a three-year period during health effects of air pollution on susceptible subpopulations," Journal of the Air and Waste Management Association, vol. 55, no. 8, pp. 1064-1076, 2005.

[11] P. Kumar, P. Fennell, and R. Britter, "Measurements of particles in the 5-1000 $\mathrm{nm}$ range close to road level in an urban street canyon," Science of the Total Environment, vol. 390, no. 2-3, pp. 437-447, 2008.

[12] T. Borsós, D. Řimnáčová, V. Ždímal et al., "Comparison of particulate number concentrations in three Central European capital cities," Science of the Total Environment, vol. 433, pp. 418426, 2012.

[13] P. Kumar, A. Robins, S. Vardoulakis, and R. Britter, "A review of the characteristics of nanoparticles in the urban atmosphere and the prospects for developing regulatory controls," Atmospheric Environment, vol. 44, no. 39, pp. 5035-5052, 2010.

[14] Directive 2008/50/EC of the European Parliament and of the Council of 21 May 2008 on ambient air quality and cleaner air for Europe.

[15] A. Held, A. Zerrath, U. McKeon et al., "Aerosol size distributions measured in urban, rural and high-alpine air with an electrical low pressure impactor (ELPI)," Atmospheric Environment, vol. 42, no. 36, pp. 8502-8512, 2008.

[16] P. Kumar, L. Morawska, and R. M. Harrison, "Nanoparticles in European cities and associated health impacts," in Handbook of
Environmental Chemistry Air Quality in Europe, M. Viana, Ed., pp. 339-365, Springer, Berlin, Germany, 2013.

[17] J. P. Shi, A. A. Khan, and R. M. Harrison, "Measurements of ultrafine particle concentration and size distribution in the urban atmosphere," Science of the Total Environment, vol. 235, no. 1-3, pp. 51-64, 1999.

[18] J. Ruuskanen, T. Tuch, H. Ten Brink et al., "Concentrations of ultrafine, fine and PM2.5 particles in three European cities," Atmospheric Environment, vol. 35, no. 21, pp. 3729-3738, 2001.

[19] B. Wehner and A. Wiedensohler, "Long term measurements of submicrometer urban aerosols: statistical analysis for correlations with meteorological conditions and trace gases," Atmospheric Chemistry and Physics, vol. 3, no. 3, pp. 867-879, 2003.

[20] N. Bukowiecki, J. Dommen, A. S. H. Prévôt, E. Weingartner, and U. Baltensperger, "Fine and ultrafine particles in the Zürich (Switzerland) area measured with a mobile laboratory: an assessment of the seasonal and regional variation throughout a year," Atmospheric Chemistry and Physics, vol. 3, no. 5, pp. 14771494, 2003.

[21] T. Hussein, A. Puustinen, P. P. Aalto, J. M. Mäkelä, K. Hämeri, and M. Kulmala, "Urban aerosol number size distributions," Atmospheric Chemistry and Physics, vol. 4, no. 2, pp. 391-411, 2004.

[22] C. H. Jeong, G. J. Evans, P. K. Hopke, D. Chalupa, and M. J. Utell, "Influence of atmospheric dispersion and new particle formation events on ambient particle number concentration in Rochester, United States, and Toronto, Canada," Journal of the Air and Waste Management Association, vol. 56, no. 4, pp. 431443, 2006.

[23] K. F. Moore, Z. Ning, L. Ntziachristos, J. J. Schauer, and C. Sioutas, "Daily variation in the properties of urban ultrafine aerosol-part I: physical characterization and volatility," Atmospheric Environment, vol. 41, no. 38, pp. 8633-8646, 2007.

[24] E. Roth, D. Kehrli, K. Bonnot, and G. Trouvé, "Size distributions of fine and ultrafine particles in the city of Strasbourg: correlation between number of particles and concentrations of $\mathrm{NO}_{x}$ and $\mathrm{SO}_{2}$ gases and some soluble ions concentration determination," Journal of Environmental Management, vol. 86, no. 1, pp. 282-290, 2008.

[25] I. Salma, T. Borsòs, T. Weidinger et al., "Production, growth and properties of ultrafine atmospheric aerosol particles in an urban environment," Atmospheric Chemistry and Physics, vol. 11, no. 3, pp. 1339-1353, 2011.

[26] I. Salma, T. Borsós, P. Aalto, and M. Kulmala, “Time-resolved number concentrations and size distribution of aerosol particles in an urban road tunnel," Boreal Environment Research, vol. 16, no. 4, pp. 262-272, 2011.

[27] L. Morawska, Z. Ristovski, E. R. Jayaratne, D. U. Keogh, and X. Ling, "Ambient nano and ultrafine particles from motor vehicle emissions: characteristics, ambient processing and implications on human exposure," Atmospheric Environment, vol. 42, no. 35, pp. 8113-8138, 2008.

[28] P. Kumar, M. Ketzel, S. Vardoulakis, L. Pirjola, and R. Britter, "Dynamics and dispersion modelling of nanoparticles from road traffic in the urban atmospheric environment-a review," Journal of Aerosol Science, vol. 42, no. 9, pp. 580-603, 2011.

[29] J. Pey, X. Querol, A. Alastuey, S. Rodríguez, J. P. Putaud, and R. van Dingenen, "Source apportionment of urban fine and ultrafine particle number concentration in a Western Mediterranean city," Atmospheric Environment, vol. 43, no. 29, pp. 4407-4415, 2009. 
[30] U. Pöschl, "Atmospheric aerosols: composition, transformation, climate and health effects," Angewandte Chemie-International Edition, vol. 44, no. 46, pp. 7520-7540, 2005.

[31] W. Rogula-Kozłowska, B. Kozielska, B. Błaszczak, and K. Klejnowski, "The mass distribution of particle-bound PAH among aerosol fractions: a case-study of an urban area in Poland," in Organic Pollutants Ten Years After the Stockholm ConventionEnvironmental and Analytical Update, T. Puzyn and A. MostragSzlichtyng, Eds., InTech, Rijeka, Croatia, 2012.

[32] K. Juda-Rezler, M. Reizer, and J. P. Oudinet, "Determination and analysis of PM10 source apportionment during episodes of air pollution in Central Eastern European urban areas: the case of wintertime 2006," Atmospheric Environment, vol. 45, no. 36, pp. 6557-6566, 2011.

[33] J. S. Pastuszka, W. Rogula-Kozłowska, and E. Zajusz-Zubek, "Characterization of PM10 and PM2.5 and associated heavy metals at the crossroads and urban background site in Zabrze, Upper Silesia, Poland, during the smog episodes," Environmental Monitoring and Assessment, vol. 168, no. 1-4, pp. 613-627, 2010.

[34] W. Rogula-Kozłowska, K. Klejnowski, P. Rogula-Kopiec, B. Mathews, and S. Szopa, "A study on the seasonal mass closure of ambient fine and coarse dusts in Zabrze, Poland," Bulletin of Environmental Contamination and Toxicology, vol. 88, no. 5, pp. 722-729, 2012.

[35] K. Klejnowski, J. S. Pastuszka, W. Rogula-Kozłowska, E. Talik, and A. Krasa, "Mass size distribution and chemical composition of the surface layer of summer and winter airborne particles in Zabrze, Poland," Bulletin of Environmental Contamination and Toxicology, vol. 88, no. 2, pp. 255-259, 2012.

[36] W. Rogula-Kozłowska, I. Sówka, B. Mathews, K. Klejnowski, A. Zwoździak, and K. Kwiecińska, "Size-resolved water-soluble ionic composition of ambient particles in an urban area in Southern Poland," Journal of Environmental Protection, vol. 4, no. 4, pp. 371-379, 2013.

[37] A. Laitinen, J. Hautanen, J. Keskinen et al., "Real time measurement of the size distribution of urban air aerosols with electrical low pressure impactor," Journal of Aerosol Science, vol. 27, supplement 1, pp. S299-S300, 1996.

[38] P. Ahlvik, L. Ntziachristos, J. Keskinen, and A. Virtanen, "Real time measurements of diesel particle size distribution with an electrical low pressure impactor," SAE 980410, 1998.

[39] C. van Gulijk, J. M. Schouten, J. C. M. Marijnissen, M. Makkee, and J. A. Moulijn, "Restriction for the ELPI in diesel particulate measurements," Journal of Aerosol Science, vol. 32, no. 9, pp. 1117-1130, 2001.

[40] C. van Gulijk, J. C. M. Marijnissen, M. Makkee, J. A. Moulijn, and A. Schmidt-Ott, "Measuring diesel soot with a scanning mobility particle sizer and an electrical low-pressure impactor: performance assessment with a model for fractal-like agglomerates," Journal of Aerosol Science, vol. 35, no. 5, pp. 633-655, 2004.

[41] P. O. Witze, R. E. Chase, M. M. Maricq, D. H. Podsiadlik, and $\mathrm{N}$. Xu, "Time resolved measurements of exhaust PM for FTP-75 comparison of LII, ELPI, and TEOM techniques," SAE Technical Paper Series 2004-01-096, 2004.

[42] M. M. Maricq, D. H. Podsiadlik, and R. E. Chase, "Size distributions of motor vehicle exhaust PM: a comparison between ELPI and SMPS measurements," Aerosol Science and Technology, vol. 33, no. 3, pp. 239-260, 2000.
[43] M. M. Maricq, N. Xu, and R. E. Chase, "Measuring particulate mass emissions with the electrical low pressure impactor," Aerosol Science and Technology, vol. 40, no. 1, pp. 68-79, 2006.

[44] Dekati Ltd, Application Note: ELPI in Automotive Application, 2007.

[45] W. Rogula-KozŁowska, B. Błaszczak, K. Klejnowski, A. Krasa, and S. Szopa, "Concentrations of PM2.5, PM2.5-10and pmrelated elements at two heights in an Urban background area in Zabrze (Poland)," Archives of Environmental Protection, vol. 37, no. 2, pp. 31-47, 2011.

[46] G. Lonati, M. Crippa, V. Gianelle, and R. van Dingenen, "Daily patterns of the multi-modal structure of the particle number size distribution in Milan, Italy," Atmospheric Environment, vol. 45, no. 14, pp. 2434-2442, 2011.

[47] G. Hoek, H. Boogaard, A. Knol et al., "Concentration response functions for ultrafine particles and all-cause mortality and hospital admissions: results of a European expert panel elicitation," Environmental Science and Technology, vol. 44, no. 1, pp. 476482, 2010.

[48] M. Kandlikar, G. Ramachandran, A. Maynard, B. Murdock, and W. A. Toscano, "Health risk assessment for nanoparticles: a case for using expert judgment," Journal of Nanoparticle Research, vol. 9, no. 1, pp. 137-156, 2007.

[49] L. A. Sgro, A. D’Anna, and P. Minutolo, "On the characterization of nanoparticles emitted from combustion sources related to understanding their effects on health and climate," Journal of Hazardous Materials, vol. 211-212, pp. 420-426, 2012.

[50] L. E. Murr and K. M. Garza, "Natural and anthropogenic environmental nanoparticulates: their microstructural characterization and respiratory health implications," Atmospheric Environment, vol. 43, no. 17, pp. 2683-2692, 2009.

[51] M. W. Frampton, "Systemic and cardiovascular effects of airway injury and inflammation: ultrafine particle exposure in humans," Environmental Health Perspectives, vol. 109, supplement 4, pp. 529-532, 2001.

[52] A. Nel, "Air pollution-related illness: effects of particles," Science, vol. 308, no. 5723, pp. 804-806, 2005.

[53] R. L. Johnson Jr., "Relative effects of air pollution on lungs and heart," Circulation, vol. 109, no. 1, pp. 5-7, 2004.

[54] C. A. Pope III and D. W. Dockery, "Health effects of fine particulate air pollution: lines that connect," Journal of the Air and Waste Management Association, vol. 56, no. 6, pp. 709-742, 2006.

[55] T. Petäjä, V. M. Kerminen, M. Dal Maso et al., "Sub-micron atmospheric aerosols in the surroundings of Marseille and Athens: physical characterization and new particle formation," Atmospheric Chemistry and Physics, vol. 7, no. 10, pp. 2705-2720, 2007.

[56] H. Boogaard, D. R. Montagne, A. P. Brandenburg, K. Meliefste, and G. Hoek, "Comparison of short-term exposure to particle number, PM10 and soot concentrations on three (sub) urban locations," Science of the Total Environment, vol. 408, no. 20, pp. 4403-4411, 2010.

[57] S. Rodríguez, R. van Dingenen, J. P. Putaud et al., "A study on the relationship between mass concentrations, chemistry and number size distribution of urban fine aerosols in Milan, Barcelona and London," Atmospheric Chemistry and Physics, vol. 7, no. 9, pp. 2217-2232, 2007.

[58] L. Morawska, V. Agranovski, and M. R. Moore, "State of epidemiological evidence for health impacts of ultrafine particles," in Proceedings 14th International IUAPPA World Congress, Brisbane, Australia, September 2007. 
[59] K. S. Woo, D. R. Chen, D. Y. H. Pui, and P. H. McMurry, "Measurement of Atlanta aerosol size distributions: observations of ultrafine particle events," Aerosol Science and Technology, vol. 34, no. 1, pp. 75-87, 2001.

[60] W. Birmili, K. Heinke, M. Pitz et al., "Particle number size distributions in urban air before and after volatilisation," Atmospheric Chemistry and Physics, vol. 10, no. 10, pp. 4643-4660, 2010.

[61] D. Mira-Salama, R. van Dingenen, C. Gruening et al., "Using Föhn conditions to characterize urban and regional sources of particles," Atmospheric Research, vol. 90, no. 2-4, pp. 159-169, 2008.

[62] M. Dal Maso, M. Kulmala, I. Riipinen et al., "Formation and growth of fresh atmospheric aerosols: eight years of aerosol size distribution data from SMEAR II, Hyytiälä, Finland," Boreal Environment Research, vol. 10, no. 5, pp. 323-336, 2005.

[63] K. Klejnowski, A. Krasa, and W. Rogula-Kozłowska, "Mass size distribution of total suspended particulates in Zabrze (Poland)," in Environmental Engineering III, A. Pawłowski and M. Dudzińska, Eds., pp. 37-43, Taylor \& Francis, London, UK, 2010.

[64] K. T. Whitby, "The physical characteristics of sulfur aerosols," Atmospheric Environment, vol. 12, no. 1-3, pp. 135-159, 1978.

[65] J. H. Seinfeld and S. N. Pandis, Atmospheric Chemistry and Physics, from Air Pollution to Climate Change, John Wiley \& Sons, New York, NY, USA, 1998.

[66] M. Väkevä, K. Hämeri, T. Puhakka, E. D. Nilsson, H. Hohti, and J. M. Mäkelä, "Effects of meteorological processes on aerosol particle size distribution in an urban background area," Journal of Geophysical Research D, vol. 105, no. 8, pp. 9807-9821, 2000.

[67] M. Kulmala, H. Vehkamäki, T. Petäjä et al., "Formation and growth rates of ultrafine atmospheric particles: a review of observations," Journal of Aerosol Science, vol. 35, no. 2, pp. 143176, 2004.

[68] A. Kiendler-Scharr, J. Wildt, M. D. Maso et al., "New particle formation in forests inhibited by isoprene emissions," Nature, vol. 461, no. 7262, pp. 381-384, 2009. 

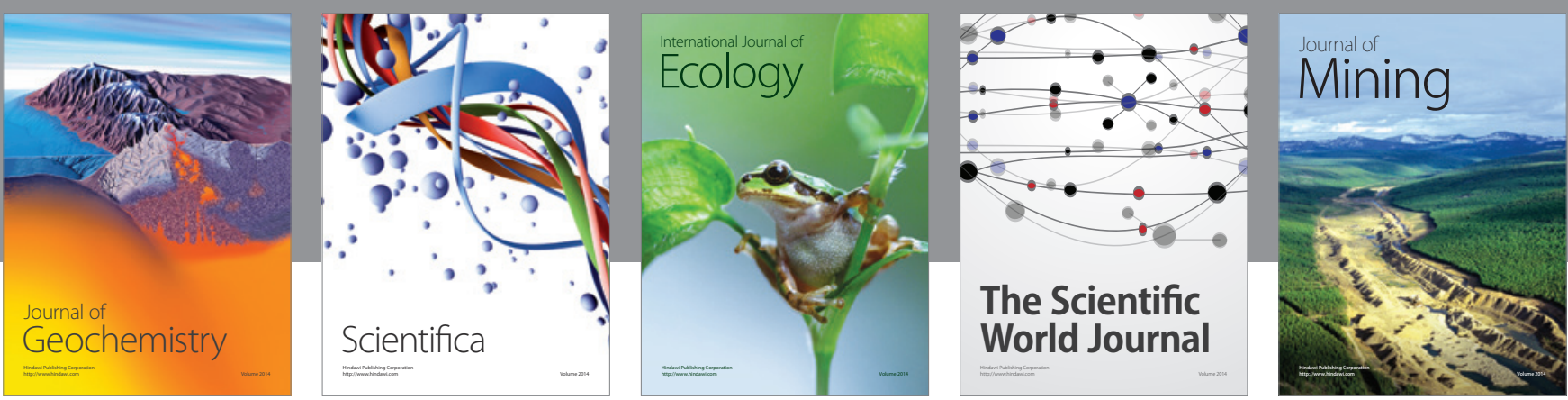

The Scientific World Journal
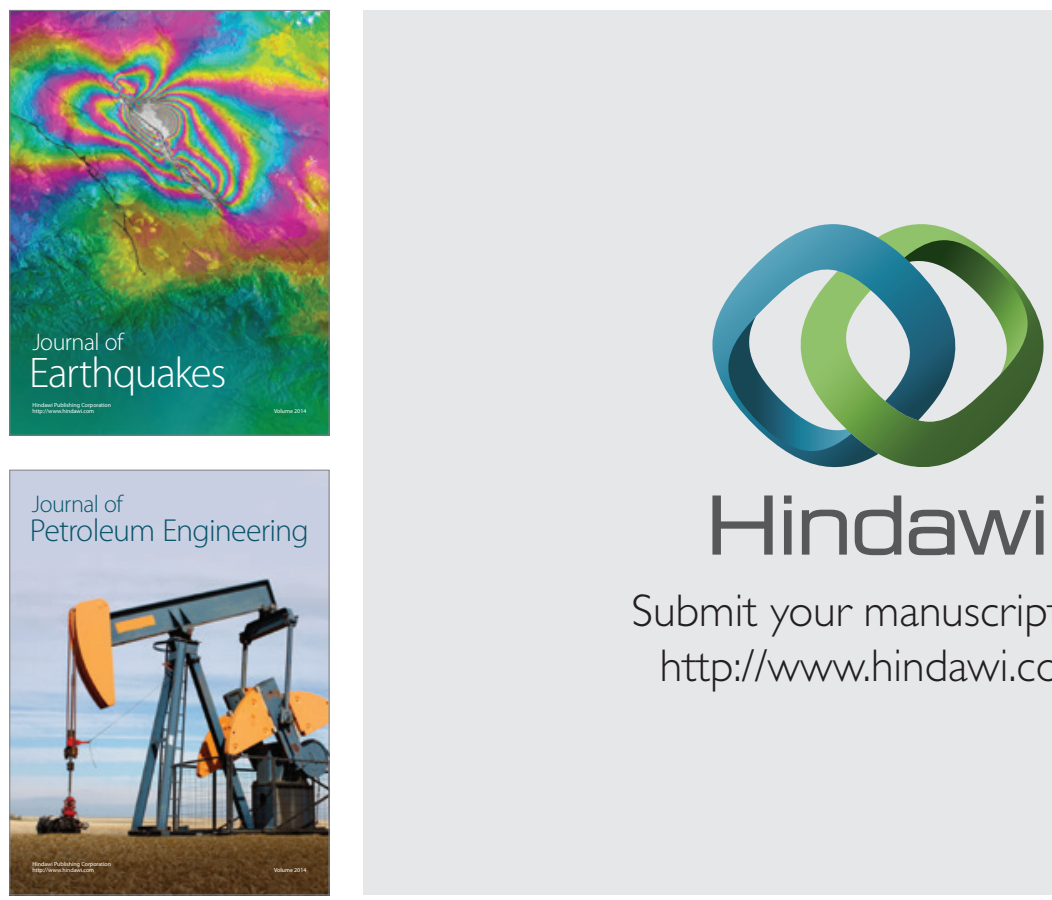

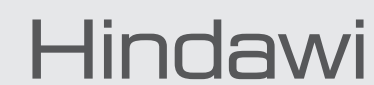

Submit your manuscripts at

http://www.hindawi.com
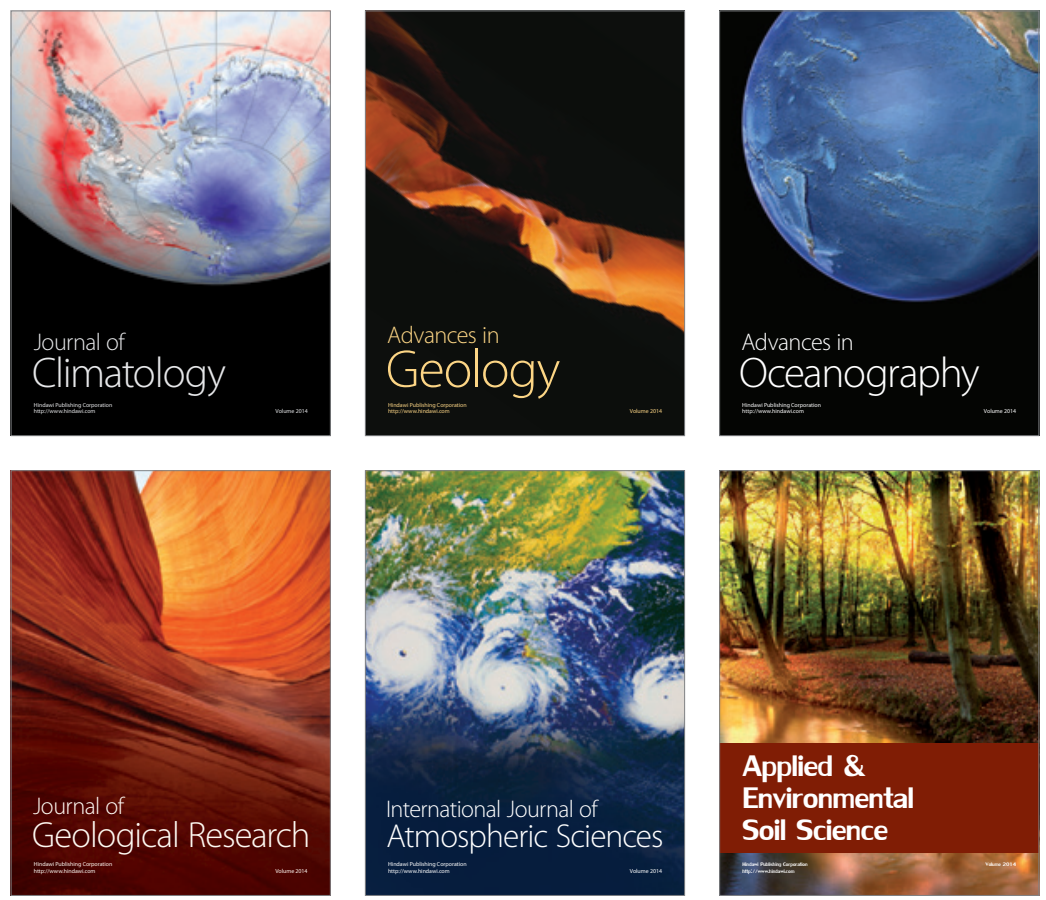
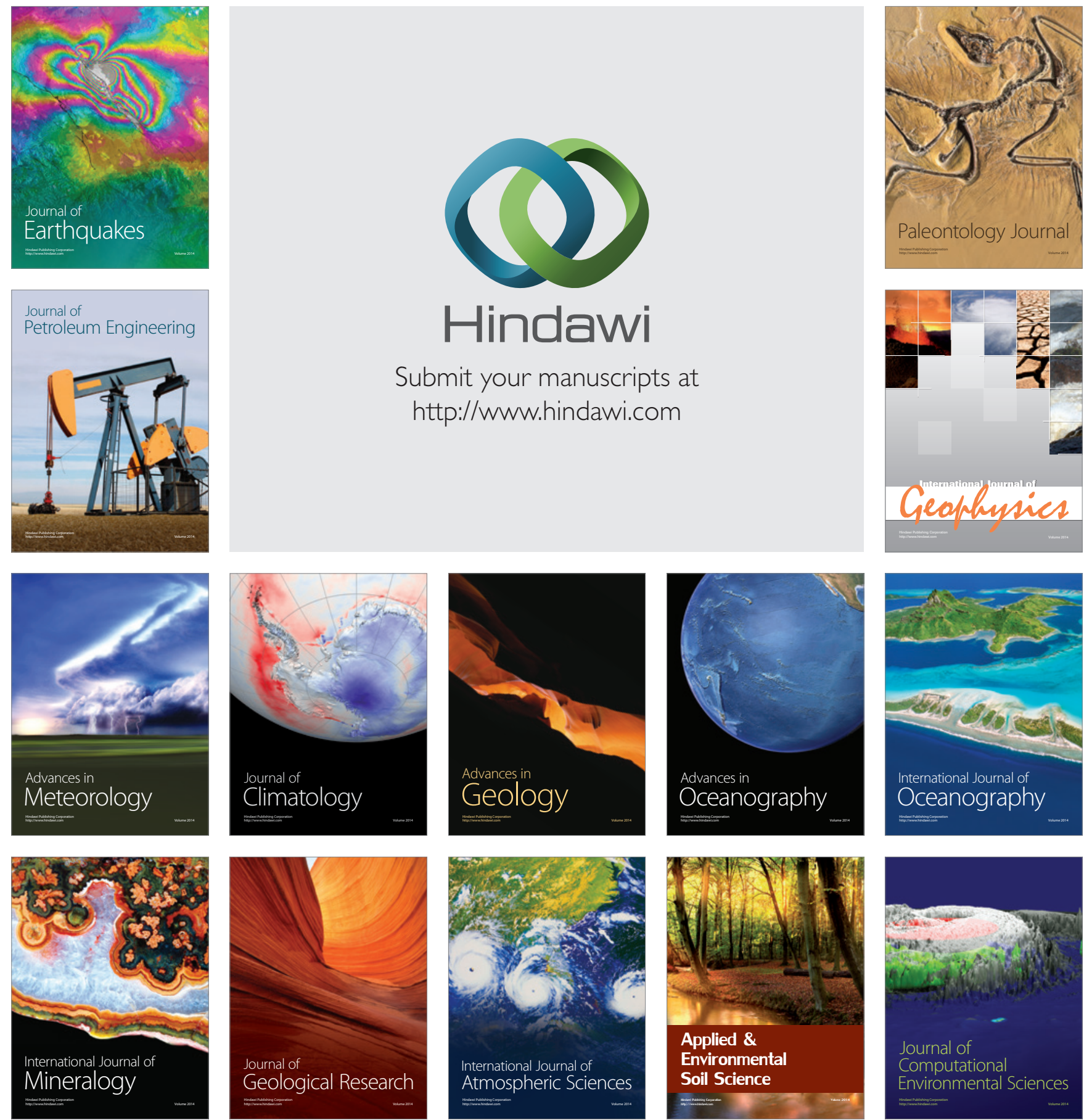